\title{
A PAISAGEM SONORA NO JOGO ELETRÔNICO FLOWER: UMA EXPERIÊNCIA MUSICAL
}

Luiz Henrique Alves Lunhani, Lucas dos Santos Rodrigues de Souza, Renan Silva Zito, Karen Rodrigues Rocha, Luciana Carolina Fernandes de Faria

Universidade do Oeste Paulista - UNOESTE, Curso de Música, Presidente Prudente, SP. Email: Luciana.carolina@gmail.com

\section{RESUMO}

Com as tecnologias digitais, o jogo eletrônico ganhou um tal potencial de imersão e interatividade, promovendo divertimento, cultura, aprendizado, arte. Este trabalho, desenvolvido a partir de uma pesquisa bibliográfica e laboratorial, teve como objetivo analisar a narrativa do jogo Flower, em seu conteúdo musical, relacionando-a ao conceito de paisagem sonora, criada por Murray Schafer (2011). Com a experiência de jogar Flowers entendemos como nossa relação com meio ambiente influencia diretamente na produção de paisagens sonoras. O jogo parece ir ao encontro com a proposta de Schafer, por um controle sobre a escuta dos ruídos criados pelo homem, para que assim o homem contemporâneo obtenha uma vida de melhor qualidade. Por fim, percebemos que por meio do videogame é possível promover aprendizado. Além de oferecer momentos de lazer e de aprendizado, os games podem nos envolver na experiência estética de uma verdadeira obra de arte.

Palavras-chave: Jogo eletrônico e Música; Paisagem sonora; Educação musical e Tecnologia; Flower e Música; Videogame e Educação.

\section{THE SOUND LANDSCAPE IN THE GAME ELECTRONIC FLOWER: A MUSICAL EXPERIENCE}

\begin{abstract}
With digital technologies, the electronic game gained such a potential of immersion and interactivity, promoting fun, culture, learning, art. This work, developed from a literature and laboratory research aimed to analyze the narrative of the game Flower in its musical content relating to the concept of soundscape, created by Murray Schafer (2011). With the experience of playing Flowers we understand how our relationship with the environment directly influences the production of soundscapes. The game seems to meet with the proposed Schafer, for control over listening to the noise created by man, so that contemporary man get a life of better quality. Finally, we realize that through the game can promote learning. In addition to offering leisure and learning moments, the games can get involved in the aesthetic experience of a work of art.

Keywords: Eletronic Games and Music; Soundscape; Music Education and Technologie, Flower and Music, Videogame and Education
\end{abstract}




\section{INTRODUÇÃO}

O jogo é um fenômeno cultural que desempenha uma função social, biológica e significativa para o ser humano e para os animais. É possível afirmar, segundo Huizinga (2008), que o jogo é anterior à civilização humana pois se percebe nas ações dos animais elementos essenciais do jogo como o prazer e o divertimento. Em outras línguas é possível perceber uma unidade terminológica entre "jogar" e "brincar", como os verbos to play, spielen, jouer, jugar, associação não possível na língua portuguesa.

Para Huizinga (2008, p. 6) "Encontramos o jogo na cultura, como elemento dado existente antes da própria cultura, acompanhando-a e marcando-a desde as mais distantes origens até a fase de civilização em que agora nos encontramos".

Assim, os jogos fazem parte dos costumes da humanidade desde as mais antigas civilizações, é uma ação natural do ser humano. Por conta de seu caráter envolvente e lúdico, o jogo é, também, considerado um recurso pedagógico muito importante, sobretudo nos anos iniciais da formação. Hoje, numa sociedade marcada pela tecnologia digital, percebemos como os jogos eletrônicos estão expressivamente presentes no cotidiano das pessoas, seja como forma de entretenimento ou mesmo para a Educação.

Já conhecemos jogos que nos permitem realizar exercícios, dançar, conhecer novos lugares, vivenciar momentos históricos, superar desafios e até praticar esportes, tudo na nossa sala de estar. Perceber as potencialidades que estes jogos eletrônicos têm de auxiliar a Educação é um assunto emergente e tem apontado belos e interessantes caminhos à pesquisadores de diversas áreas, mesmo com jogos que não foram, a priori, desenvolvidos com objetivo educacional.

Segundo Murray (2003), o jogo eletrônico é caracterizado por três fatores: imersão, agência e transformação, que o torna envolvente e atrativo. A imersão, característica de todo jogo, envolve o jogador e exige dele uma ação, sem a qual o jogo não acontece. $O$ aspecto imersivo, defendido também por Huizinga (2008) e por Santaella e Feitosa (2009), transporta o jogador a um outro "ambiente", envolvendo seu sistema perceptivo (visão, audição e tato). Fazendo um paralelo à Educação, esta ação do aluno em seu processo de formação é fundamental para que ele aprenda de forma significativa e autônoma.

A característica da agência torna o jogo atrativo pois permite a ação do jogador no espaço virtual, permite que ele tome suas decisões diante dos desafios apresentados. Estas decisões são registradas pelo jogo que, a partir deste mapeamento da ação do jogador, apresenta novos desafios, tornando o jogador autor de sua história no jogo. A transformação abre espaço para a criatividade do jogador, que com sua agência no jogo, transforma seu espaço. No processo de Educação, esta autonomia é igualmente essencial para a formação do aluno, que deve ter consciência de sua condição como responsável pelo seu próprio desenvolvimento, sua autoprodução.

Além disso, o jogo tem uma carga lúdica que o torna atrativo. Mesmo brincando, divertindo-se, o jogador/aluno aprende. Aprender é uma condição de vida aos seres humanos, assim, não é apenas dentro dos muros da escola que o aprendizado acontece. Mesmo como jogo eletrônico de entretenimento, comercial, não sendo produzido com a finalidade de ensinar, leva o jogador a produzir conhecimento para ele possa se desenvolver no jogo, tornando muito tênue a linha que separa o "aprender" do "brincar". Esta é uma experiência rica para o contexto escolar: despertar no jovem o prazer em aprender.

Mente e matéria são dimensões do fenômeno da vida e o processo de cognição nada mais é do que o próprio processo da vida. [...] Se a vida é experiência e viver nada mais do que estar experimentando algo novo a 
cada dia e a cada momento, então a vida nada mais é do que um processo de contínua aprendizagem, através do qual construímos a realidade e o saber. (MORAES, 2003, p. 46, 48)

Para Pierre Lèvy (apud NOVA; ALVEZ, 2003, p. 132):

[...] os videogames oferecem os modelos interativos a explorar. Eles simulam terrenos de aventuras, universos imaginários. Certo, trata-se de puro divertimento. Mas como não ser tocado pela coincidência dos extremos: o pesquisador que faz proliferar os cenários, explorando modelos numéricos (digitais), e a criança que joga um videogame experimentam, ambos, a escritura do futuro, a linguagem de imagens interativas, a ideografia dinâmica que permitirá simular os mundos.

Para que o jogo aconteça é necessário a ação do jogador. Desta forma, não é possível que o jogador assuma um papel meramente contemplativo, de espectador. O jogo não fornece respostas prontas ao jogador, mas estimula-o a refletir, conhecer, arriscar. É preciso que o jogador se envolva, tome suas decisões, busque conhecimento para superar os desafios. Assim como o aluno em sua formação autônoma, como defendia Paulo Freire (1996).

Cada vez mais a tecnologia avança a passos largos, e as crianças e jovens em idade escolar acompanham toda essa avalanche eletrônica em tempo real. Em contrapartida, a escola ainda parece não saber como reagir a esse avanço, tanto pela já conhecida falta de estrutura física e material das nossas escolas, como também por metodologias que parecem ainda não dialogar muito bem com tudo que temos disponível. Pareceria um tanto utópico sonhar como salas de aula equipadas com videogames de última tecnologia, contudo, é necessário pensar a Educação do século XXI olhando para frente, e não apenas para os tradicionais meios já não tão adequados à dinâmica de vida do aluno contemporâneo. Assim, com os tablets, smartphones, as lousas digitais e outros gadgets, acreditamos que tais tecnologias podem sem, a médio ou longo prazo, estarem presentes na escola de maneira formal.

O quadro negro, giz, cadernos e cartilhas não têm sido eficientes em envolver os alunos no processo de aprendizagem e despertar interesse e prazem em aprender. A facilidade com que obtemos informações através da internet, e o atraso das escolas com relação a esses novos meios de comunicação com o mundo, tornam nossas instituições muito menos atrativas aos alunos. Uma forma então de tornar as aulas muito mais interessantes, é incluir na sala de aula alguns destes novos meios como ferramentas de suporte ao ensino.

A partir de tais premissas e da nossa própria formação enquanto alunos e jogadores destes games, pesquisamos possibilidades de proporcionar uma experiência mais interativa e dinâmica por meio dos jogos eletrônicos na Educação Musical. Destarte, este artigo tem como objetivo apresentar os resultados de uma pesquisa realizada que buscou analisar a narrativa do jogo Flower, em seu conteúdo musical, relacionando-a ao conceito de paisagem sonora, criada por Murray Schafer. Desta forma busca-se demonstrar que fazendo uso de um jogo eletrônico pode-se discutir e experienciar a Paisagem Sonora por um meio imersivo, interativo e audiovisual dos games.

\section{METODOLOGIA}

A plataforma usada foi o Playstation 3, que, por meio do contato com o game, foi realizada a observação e análise das fases e modos de interação, determinando seu funcionamento, sua estrutura e qual a proximidade da experiência do jogo com a estética e o conceito de Paisagem Sonora. A partir de tal análise, buscou-se fazer uma conexão entre a definição de Schafer (2011) sobre a Paisagem Sonora, como este tema é abordado pela narrativa 
do jogo, de que forma este aparato eletrônico inicialmente pensado para momentos de lazer pode tornar-se uma ferramenta auxiliar para experimentar e contextualizar, de forma atrativa e prática, um conceito musical em sala de aula.

\section{RESULTADOS}

Este game é desenvolvido pela Thatgamecompany, desenvolvedora privada de jogos eletrônicos norte-americana, e está disponível para diferentes plataformas como Playstation 3 e Playstation 4, e oferece ao jogador uma experiência de composição musical fazendo uso de elementos sonoros disponíveis nos diferentes cenários apresentados em cada nível do jogo.

A companhia foca-se em criar jogos eletrônicos que provoquem respostas emocionais nos jogadores, "entretenimento interativo atemporal que faça uma mudança positiva na psique humana". Seus funcionários afirmaram que, apesar de não se oporem a produção de jogos de ação, acreditam que já há bastante títulos desse gênero lançados anualmente pela indústria. Ao criar um jogo, os funcionários da Thatgamecompany começam mapeando o que querem que o jogador sinta, ao invés de estabelecer mecânicas de jogo. Os funcionários afirmaram que não planejam produzir jogos grandes e voltados ao grande público, achando que a pressão por vendas iria reprimir a inovação. (THATGAMECOMPANY, 2016)

No game além daquilo que já encontramos normalmente em todos os jogos, como completar objetivos para liberar uma nova fase, há também toda uma preocupação com aquilo que vemos e ouvimos. Flower tem um caráter poético, pois sua construção não parte de um pressuposto de competição contra alguém ou contra a "máquina", mas sim da sensação que se tem ao jogar e a de uma apreciação audiovisual.

Este jogo, ao contrário de outros tipos de jogos em que o foco está em oferecer fases com diferentes objetivos e níveis de dificuldade, possuiu uma narrativa emotiva, baseada em uma trama leve, simplista. O jogo não possui limite de tempo, pontuação, inimigos e quantidade de vidas. O jogador controla o vento, que ao passar pelas flores dispostas no ambiente virtual, vai ganhando pétalas de diversas cores e timbres, revivendo partes do cenário. Além de toda a beleza visual, o jogo não apresenta nenhum texto ou diálogo, voltando toda a atenção para a trilha sonora. Cada vez que tocamos as flores presentes no jogo, ouvimos um som e desencadeamos uma "evolução" da trilha sonora. Os timbres encontrados nas diferentes flores do cenário são sons de piano, cordas, flautas e fagotes. A quantidade de instrumentos na trilha sonora muda conforme a quantidade de pétalas capturadas pelo jogador. Assim, a ação do jogador é que "molda" a trilha de cada fase, sendo ele o compositor de sua própria paisagem sonora.

Apesar de não apresentar nenhum diálogo, a narrativa do jogo acontece durante as seis fases. Na fase inicial, o jogador se encontra em uma paisagem campestre, formada apenas por árvores, flores, pedras e grama. Conforme toca as flores do ambiente, vai revitalizando a vida e a cor da paisagem, inicialmente morta. Nas fases seguintes, aparecem nos cenários, moinhos de vento, um campo noturno com algumas redes elétricas, até atingir a última fase que acontece em uma cidade, com estruturas metálicas, edifícios e fios de eletricidade que ameaçam o desempenho e mobilidade do jogador, fazendo-o perder suas pétalas ao encostar em tais estruturas. Ao concluir os desafios de encontrar e "ativar" os sons das flores de toda a fase, a cidade pálida se transforma em uma cidade colorida, alegre e brilhante.

Além dos sons dos instrumentos, é possível ouvir o som do vento, das folhas em movimento, das estruturas metálicas rangendo, das descargas elétricas, entre outros sons. Destarte, percebemos que a progressão das fases faz referência a mudança da vida rural para a 
vida urbana, e destaca como o ambiente sonoro muda durante este processo. Schafer (2011) em sua obra faz uma descrição deste mesmo fenômeno.

\section{DISCUSSÃO}

Desenvolvido por Murray Schafer (2011), compositor e educador musical canadense, o conceito de Paisagem Sonora, no original "Soundscape", busca observar e analisar os sons que compõem o nosso ambiente, tenham eles suas origens no humano, animal, industrial, estejam na zona rural ou urbana. O conceito traz à reflexão como o som no cotidiano da sociedade foi mudando com o passar do tempo, cada vez mais "poluído" com ruídos, propondo assim uma busca pelos sons naturais e por um controle sobre a escuta dos ruídos criados pelo homem, para que, assim, o homem contemporâneo obtenha uma vida de melhor qualidade através da apreciação de sons que são extremamente benéficos, como o som de pássaros ou o vento no campo.

Como define o texto da quarta-capa do livro Afinação do Mundo, de Schafer (2011)

A paisagem sonora [...] é nosso ambiente sonoro, o sempre presente conjunto de sons agradáveis e desagradáveis, fortes e fracos, ouvidos ou ignorados, com os quais vivemos. Do zumbido das abelhas ao ruído da explosão, este vasto compêndio, sempre em mutação, de cantos de pássaros, britadeiras, música de câmara, gritos, apitos de trem e barulho da chuva tem feito parte da existência humana.

Para a formação humana, aprender a perceber os sons do mundo o qual habitamos e ressignificar nossa forma de interagir com tais sons é de extrema importância. Mesmo após 8 anos da homologação da Lei 11.769/08, ainda há certa dificuldade, sobretudo entre os agentes da Educação Básica, em compreender o objetivo da música na escola. Com os conceitos tradicionais de usar a música como ferramenta para ensinar conteúdos escolares (como português e matemática), ou a concepção de que aprender música é dominar um instrumento musical, se deixa em segundo plano a meta principal e mais bonita da Educação Musical: ensinar a ouvir. A paisagem sonora abre os ouvidos para os sons do mundo e pode ser a porta de entrada para uma educação sonora.

A hegemonia da música tonal ainda é largamente reproduzida pela cultura de massa, pela indústria fonográfica e ainda marca a formação dos professores de música nos cursos superiores. Cursos à distância, por exemplo, que acontecem por um meio que facilita a produção de música contemporânea, como a paisagem sonora, ainda se limitam em manter as tradicionais aulas de instrumentos por meio de vídeo-aulas. Não que devamos abandonar ou abolir a música tonal ou a prática dos instrumentos tradicionais na educação musical na escola, mas é necessário compreender que a tecnologia contemporânea abre possibilidades de o aluno produzir e experimentar e produzir música, sem necessitar de anos de estudo da técnica de um instrumento musical tradicional.

Compreender importância da estética musical contemporânea é entender o próprio processo do homem na história dos séculos XX e XXI. Jogando o game Flower, o jogador, por meio de sua ação no ambiente, pode apreciar, compor e fluir a paisagem sonoro do ambiente a qual está imerso. Esta experiência musical se difere das apreciações de obras clássicas do repertório europeu, que são concebidas para sem ouvidas de uma plateia, em ação puramente contemplativa e pré-concebida.

Na medida em que a apresentação não ocorre em um palco italiano e dentro de um teatro, existe a possibilidade de se vivenciar experiências estéticas completamente diferentes daquelas propiciadas pela sala de concerto. Primeiro porque se pode andar e procurar situações sonoras específicas. Segundo porque, se houver a possibilidade de interação, o 
ouvinte não será apenas mais um espectador manipulando um objeto, mas estará compondo a "obra" enquanto a experimenta dentro de um espaço onde pode se mover e buscar novas possibilidades de audição. Nesse caso, essa experiência deixa de ser apenas sonora, porque, para se movimentar, o participante (ex-expectador) precisa se orientar no meio por outros modos de atenção. (OLIVEIRA, 2010, p. 10)

Desta forma, a experiência do jogo aproxima a música da realidade de todos os seres humanos, não apenas daqueles poucos privilegiados que estudam um instrumento musical especificamente, e abre nossos ouvidos para que, percebendo o mundo sonoro, possamos melhorar nossa ação nele.

A temática do presente trabalho surgiu devido à nova tendência contemporânea de se refletir e compor música, abandonando a primazia das frequências definidas, tão importante no sistema tonal, para privilegiar os timbres dos sons que nos cercam. Produzimos constantemente paisagens sonoras e também somos afetados por ela, dessa maneira, somos todos simultaneamente músicos, compositores e ouvintes dessa nova música. Com a experiência de jogar Flowers entendemos como nossa relação com meio ambiente influencia diretamente na produção de paisagens sonoras. Com o avanço da revolução industrial e elétrica as paisagens sonoras deixaram de soarem Hi-fi para soarem Lo-fi, como estão explicadas historicamente por Schafer (2011).

Por nossa ação no mundo, somos criadores da nossa própria paisagem sonora e esta produção afeta nossa maneira de habitar este mundo. Assim o jogo faz uma ligação, mesmo que não proposital, ao conceito de paisagem sonora.

\section{CONCLUSÃO}

Com o uso desse jogo eletrônico podemos discutir conceitos da educação musical, como a Paisagem Sonora, utilizando um meio não "tradicional", aparato já popular entre os alunos e presente no nosso dia-a-dia. A transformação de algo concebido como apenas uma forma de diversão e entretenimento, em uma ferramenta de suporte ao ensino, pode tornar as aulas mais interessantes tanto para o aluno quanto ao professor. Desta forma, os alunos identificam-se como parte fundamental do processo de aprendizagem, se sentem envolvidos e sentem prazer em aprender, tornando o limite entre aprender e brincar uma linha tênue.

Por fim, percebemos que com as tecnologias digitais, o jogo eletrônico ganhou um tal potencial de imersão e interatividade, promovendo divertimento, cultura, aprendizado, arte. Assim, por meio do videogame é possível promover conhecimento e, usando o jogo como recurso, o fazer e experienciar a música se torna fluída e prazerosa. Além de oferecer momentos de lazer e de desenvolvimento cognitivo, os games podem nos envolver na experiência estética de uma verdadeira obra de arte.

\section{REFERÊNCIAS}

FREIRE, P. Pedagogia da autonomia: saberes necessários à prática educativa. São Paulo: Paz e Terra, 1996.

HUIZINGA, J. Homo Ludens. O Jogo como elemento da cultura. 5. ed. São Paulo: Perspectiva, 2008.

LÉVY, P. Tecnologias intelectuais e modos de conhecer: nós somos o texto. Tradução de Celso Cândido. Assistência e consultoria de termos técnicos por João Batista. Disponível em: <http://www. hotnet.net/PierreLevy/nossomos.html>. Acesso em: 20 maio 2011. 
MORAES, M.C. Educar na biologia do amor e da solidariedade. Petrópolis: Vozes, 2003.

MURRAY, J. H. Hamlet no holodeck: o future da narrativa no ciberespaço. São Paulo: Itaú Cultural: Editora Unesp, 2003.

OLIVEIRA, A. L. G. Paisagem Sonora como obra híbrida: espaço e tempo na produção imagética e sonora. Semeiosis: semiótica e transdisciplinaridade em revista. [suporte eletrônico] Disponível em: $<$ http://www.semeiosis.com.br/u/35>. Acesso em 01/jul/2016.

SANTAELLA, L; FEITOZA, M. (Org.). Mapa do jogo: a diversidade cultural dos games. São Paulo: Cengage Learning, 2009.

SCHAFER, R. M. A afinação do mundo: uma exploração pioneira pela história passada e pelo atual estado do mais negligenciado aspecto do nosso ambiente: a paisagem sonora. 2. ed. São Paulo: Editora Unesp, 2011.

THATGAMECOMPANY. In: WIKIPÉDIA, a enciclopédia livre. Flórida: Wikimedia Foundation, 2016. Disponível em:

<https://pt.wikipedia.org/w/index.php?title=Thatgamecompany\&oldid=45561133 >. Acesso em: 4 jul. 2016. 